\title{
Solution Rheology of Poly(acrylic acid)-Grafted Silica Nanoparticles
}

Chongfeng Zhang ${ }^{\dagger}$, Siyang Yang ${ }^{\dagger}$, Venkat Padmanabhan ${ }^{\S}$ and Pinar Akcora ${ }^{\dagger}$,*

${ }^{\dagger}$ Department of Chemical Engineering \& Materials Science, Stevens Institute of Technology

Hoboken, NJ 07030, USA

${ }^{\S}$ Department of Chemical Engineering, Tennessee Technological University

Cookeville, TN 38505, USA

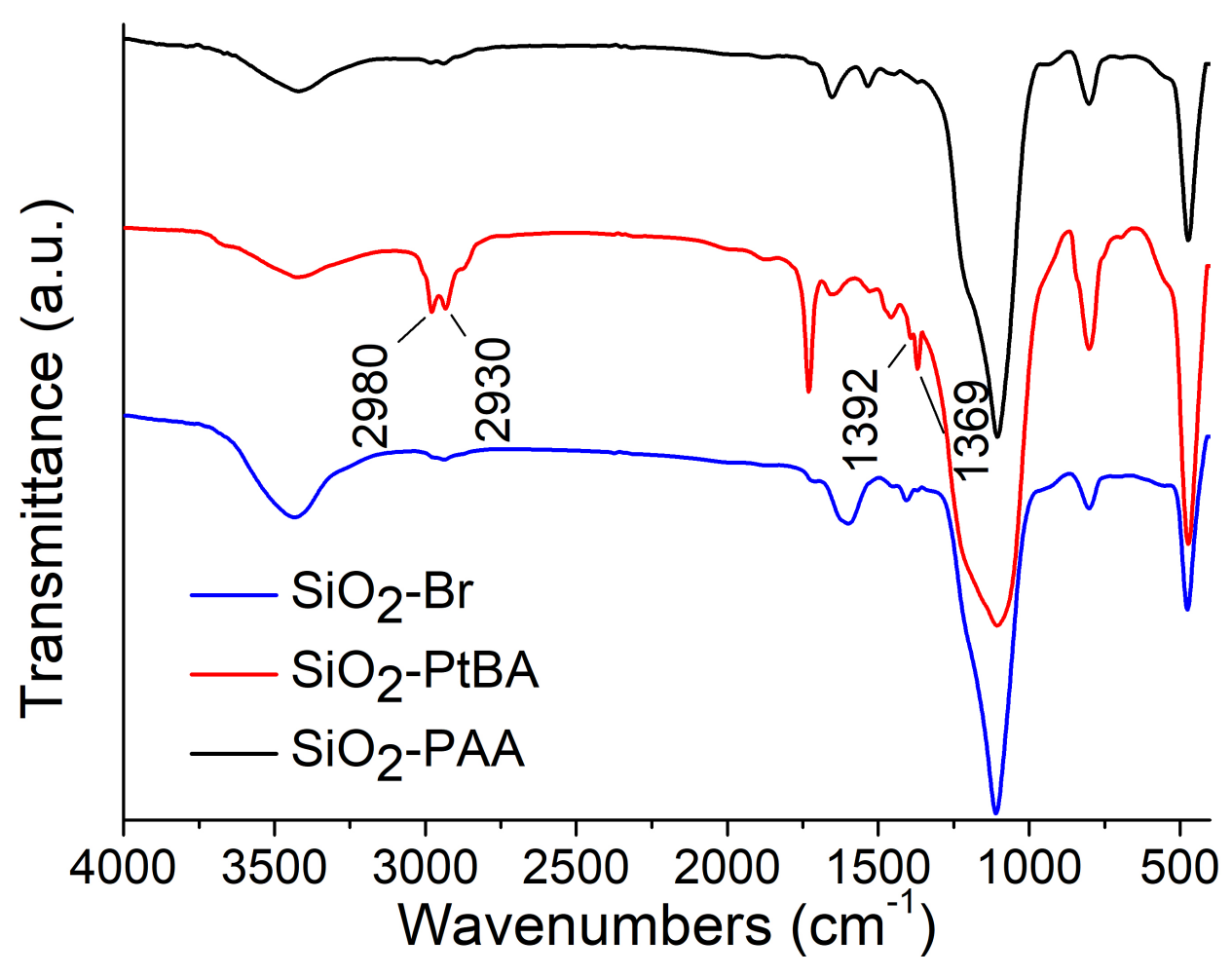

Figure S1. FTIR spectra of the synthesized $\mathrm{SiO}_{2}-\mathrm{Br}, \mathrm{SiO}_{2}-\mathrm{PtBA}, \mathrm{SiO}_{2}-\mathrm{PAA}$. 
The full hydrolysis is confirmed by the disappearance of asymmetrical stretching peaks (at 2980 and $2930 \mathrm{~cm}^{-1}$ ) and in-plane scissoring peaks (at 1392 and $1369 \mathrm{~cm}^{-1}$ ) of $-\mathrm{CH}_{3}$ in tert-butyl groups as shown in Figure S1.

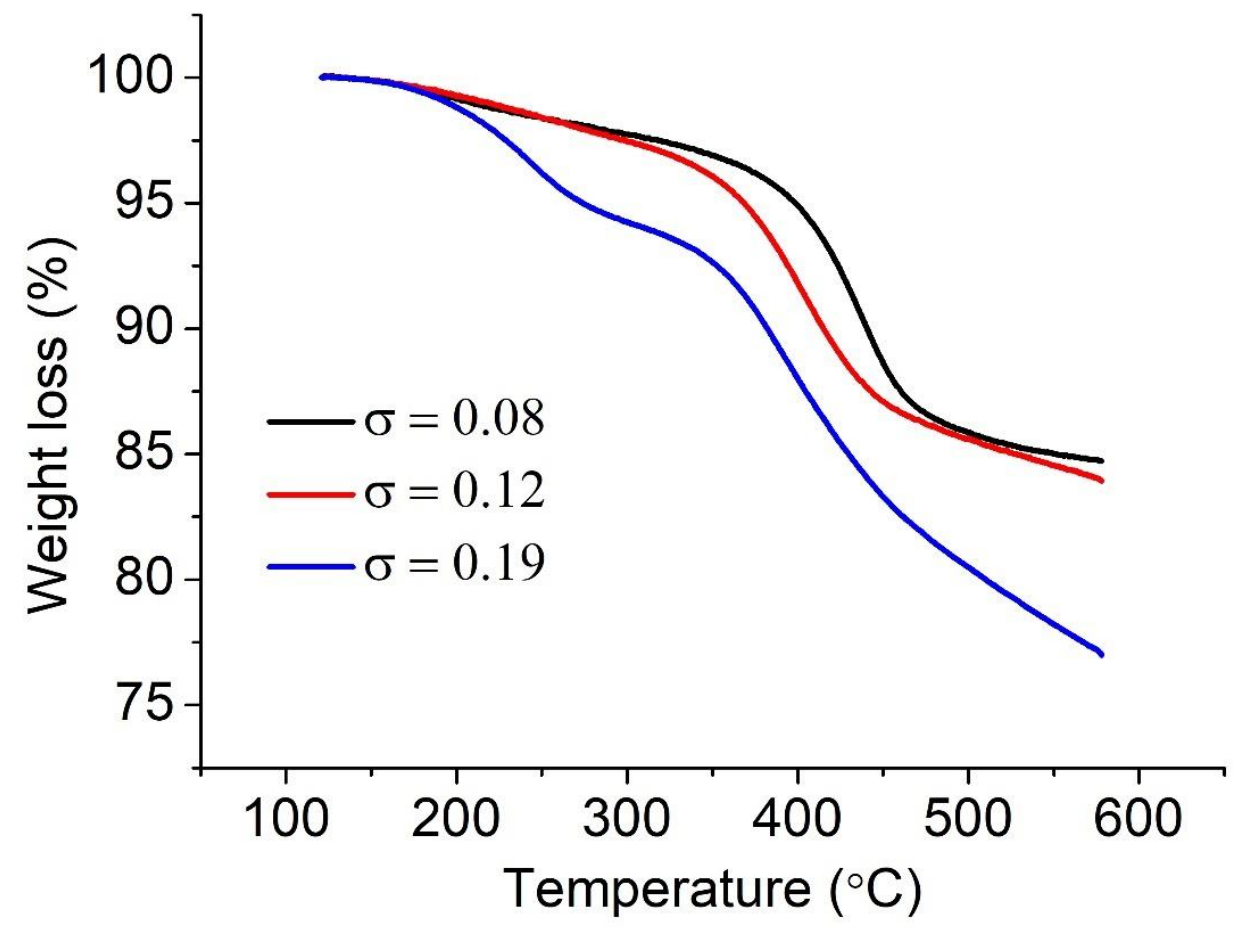

Figure S2. TGA data of the synthesized $\mathrm{SiO}_{2}-\mathrm{PAA}$ at three grafting densities of $0.08,0.12$ and 0.19 chains $/ \mathrm{nm}^{2}$. 


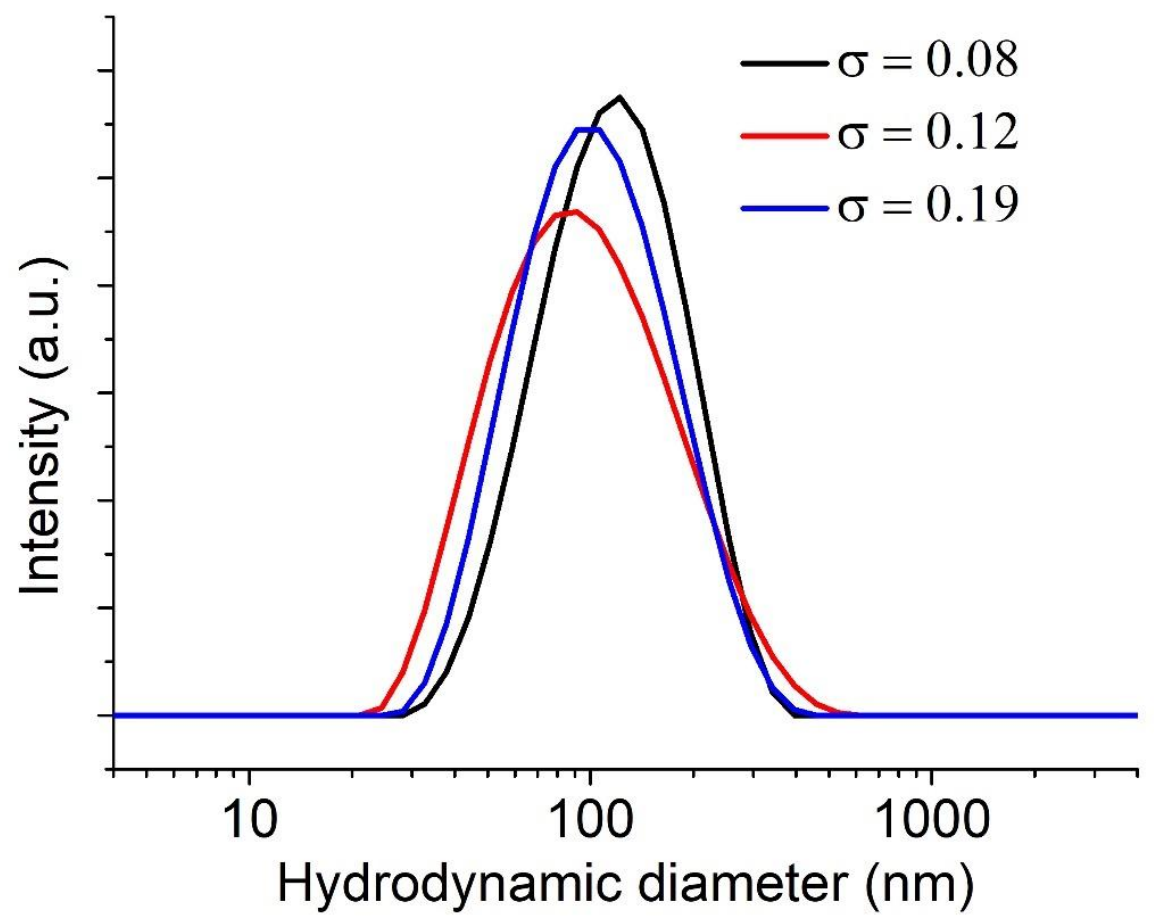

Figure S3. Size distributions of $\mathrm{SiO}_{2}$-PAA particles of varying grafting densities (in chains $/ \mathrm{nm}^{2}$ ) as labeled on the graph.

\section{Calculation of Brush Molecular Weight $\left(\mathrm{M}_{\mathrm{W}}\right)$ and Grafting Density $(\sigma)$}

Grafted shell thickness is obtained by subtracting the core radius $\left(r_{\text {core }}\right)$ from the hydrodynamic radius of grafted nanoparticles. At $\mathrm{pH}$ 9, this brush thickness was regarded as contour length $L_{C}$ because PAA chains are extended due to electrostatic repulsion by full ionization. $M_{W}$ was calculated using the equation $M_{W}=m \times N=m \times L_{C} / l . m=72 \mathrm{~g} / \mathrm{mol}$ is the monomer mass, $N$ is the number of repeating units, $l=2.5 \AA$ is the length of repeating unit, $L_{C}$ is the contour length and is measured for samples at $\mathrm{pH} 9$ using DLS. The grafting density was calculated using the equation:

$$
\sigma=\frac{w t \%_{\text {brush }}}{w t \%_{\text {core }}} \times \frac{\frac{4}{3} \rho_{\text {core }} r_{\text {core }}^{3} N_{A}}{4 \pi r_{\text {core }}^{2} M_{W}}
$$


where $\frac{w t \%_{\text {brush }}}{w t \%_{\text {core }}}$ is the relative mass ratio of grafted PAA to the core of silica nanoparticles, $\rho_{\text {core }}=2.07 \mathrm{~g} / \mathrm{cm}^{3}$ is the core density, $N_{A}$ is the Avogadro's number.

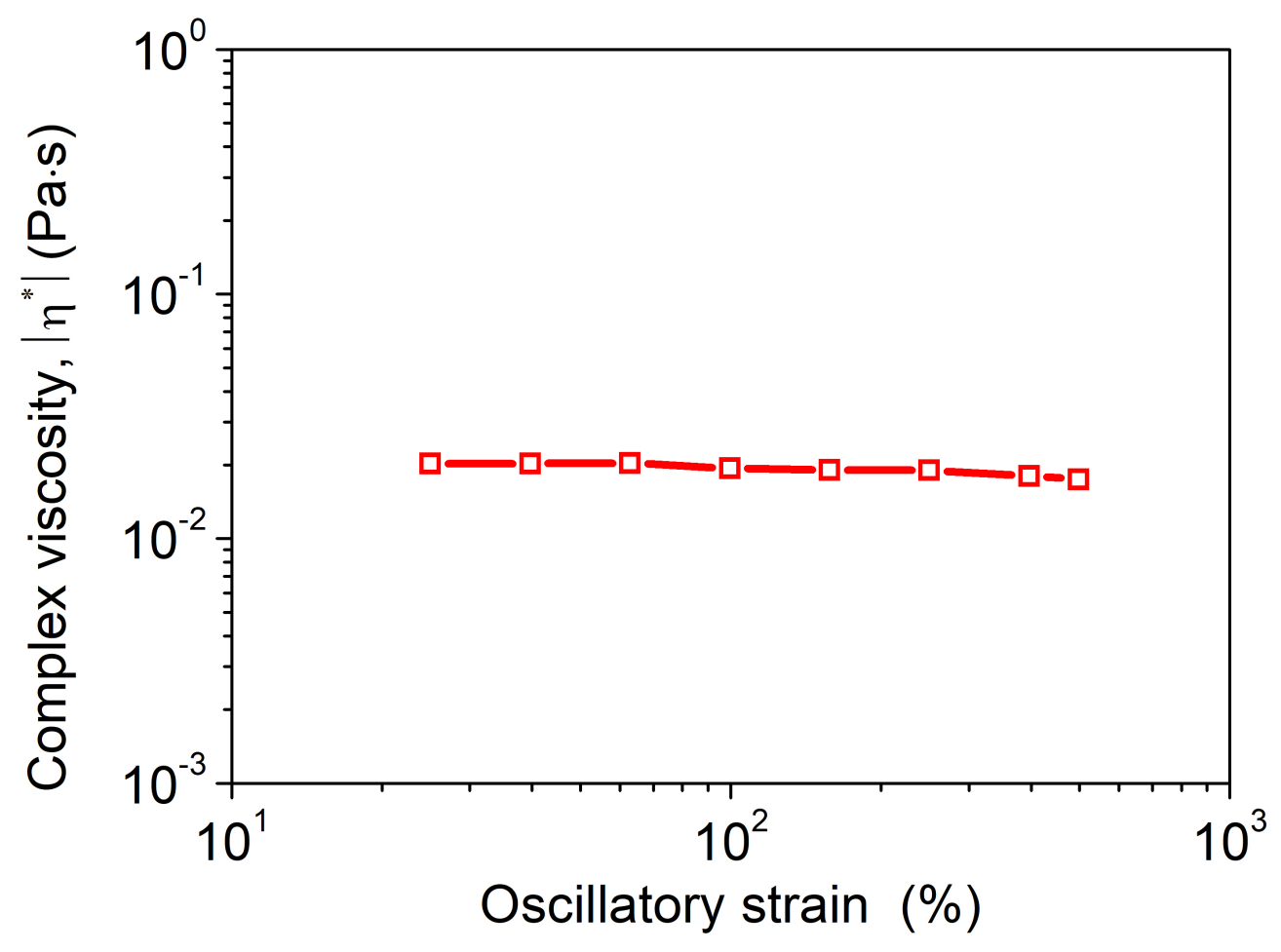

Figure S4. Strain sweep of $\mathrm{SiO}_{2}-\mathrm{PAA}$ at $\mathrm{pH} 3\left(\sigma=0.08\right.$ chains $\left./ \mathrm{nm}^{2}\right)$ at angular frequency $\omega$ $=10 \mathrm{rad} / \mathrm{s}$. 


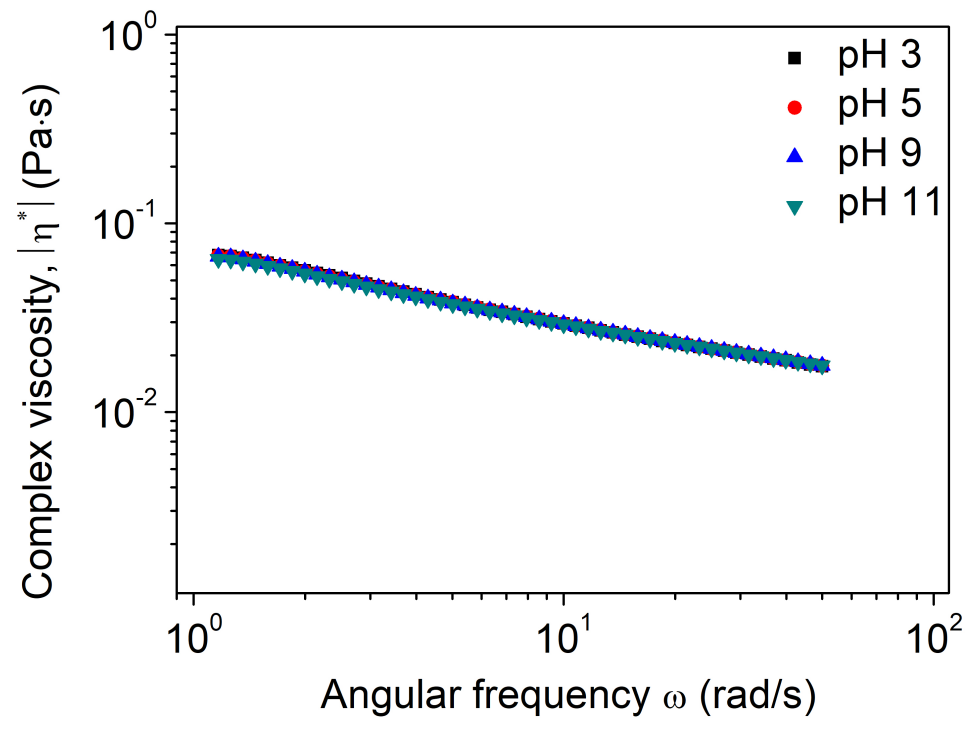

Figure S5. Complex viscosity of $\mathrm{SiO}_{2}$-PNIPAM with $\sigma \approx 0.19$ chains $/ \mathrm{nm}^{2}, \mathrm{M}_{\mathrm{W}} \approx 10,000$ $\mathrm{g} / \mathrm{mol}$ at different $\mathrm{pH}$ as a function of angular frequency. 

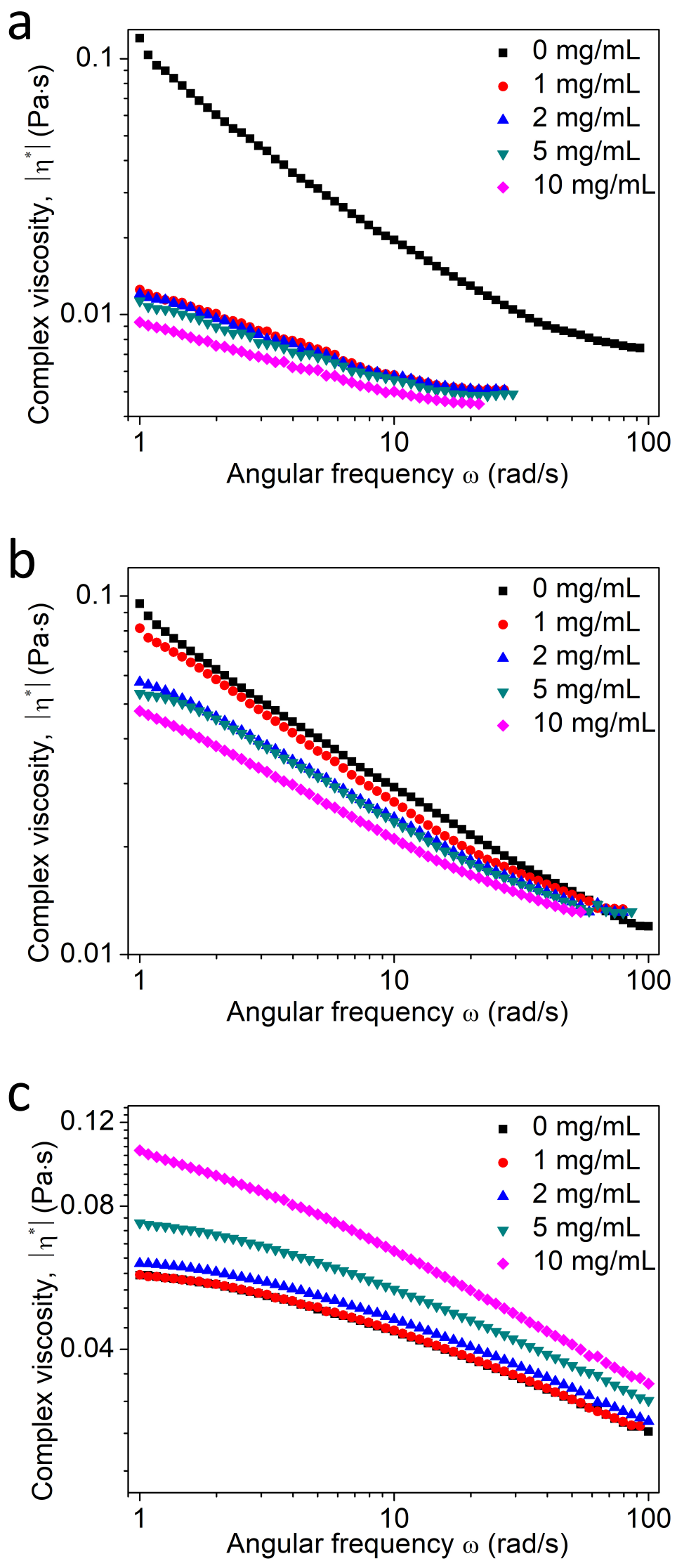

Figure S6. Effect of PVP addition on complex viscosity of $\mathrm{SiO}_{2}-\mathrm{PAA}$ for a) $\sigma=0.08$ chains $\left./ \mathrm{nm}^{2}, \mathbf{b}\right) \sigma=0.12$ chains $/ \mathrm{nm}^{2}$, and $\left.\mathbf{c}\right) \sigma=0.19$ chains $/ \mathrm{nm}^{2}$ at $\mathrm{pH} 3$. 

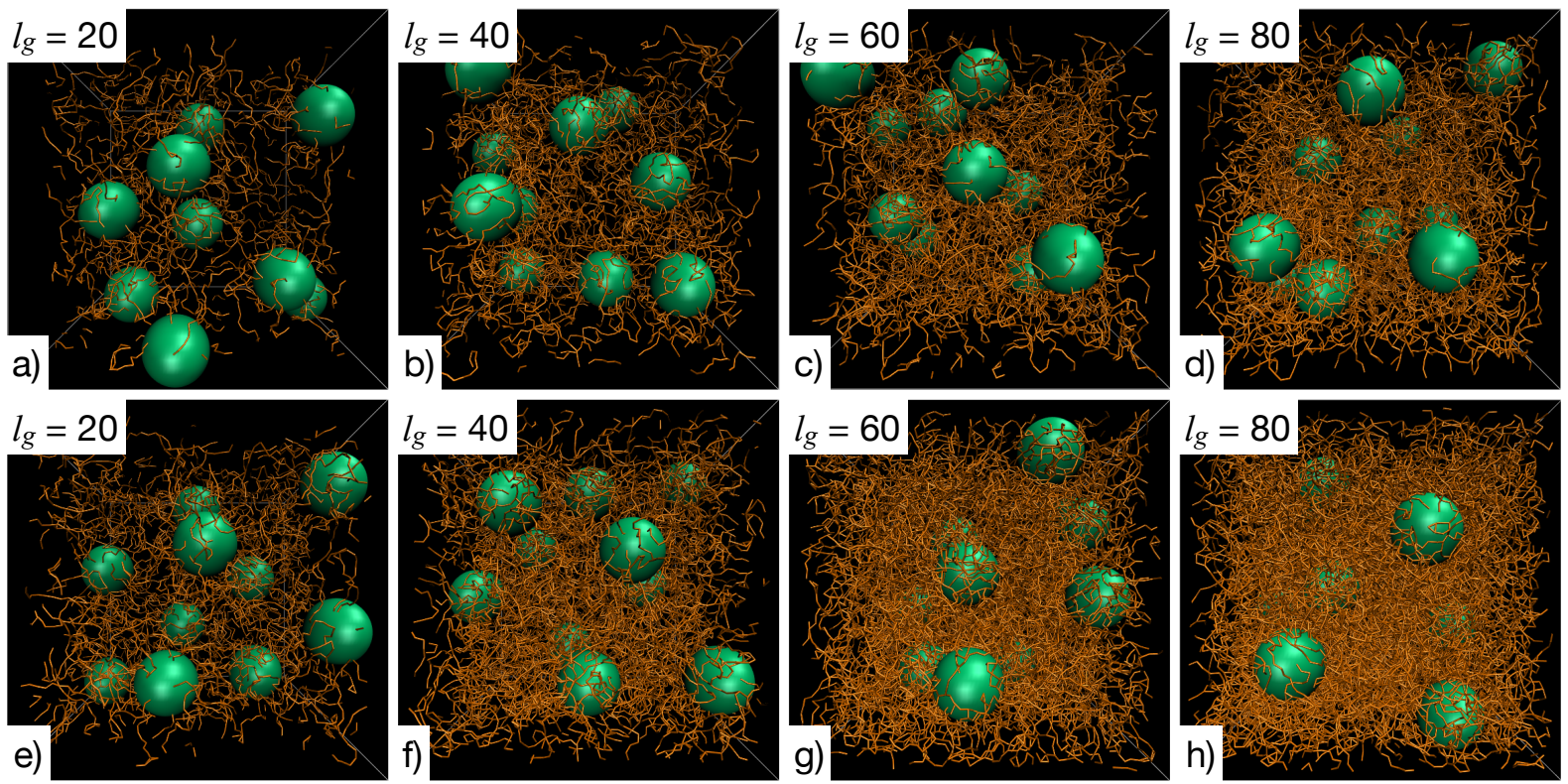

Figure S7. Grafted particle dispersions with different graft lengths for a) 0.1 and b) 0.2 chains $/ \sigma^{2}$ graft density.
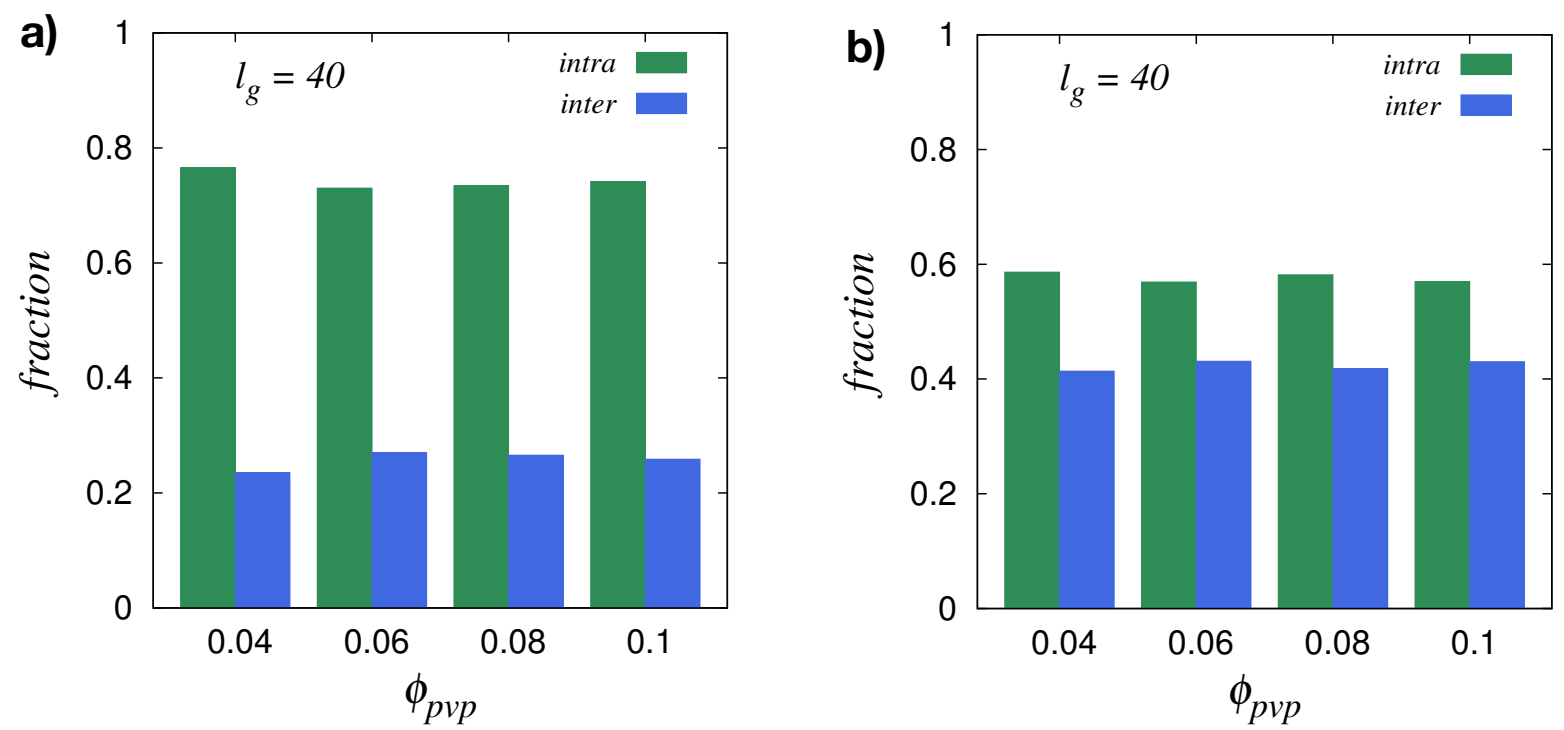

Figure S8. The number fraction of hydrogen bondings between inter-particles and intra-particles at varying PVP amounts at a) 0.1 chains $/ \sigma^{2}$ b) 0.2 chains $/ \sigma^{2}$ graft density. 